\title{
Photobiomodulation therapy to treat neuropathic oral pain after contagion by COVID-19
}

Terapia de fotobiomodulação no tratamento de dor oral neuropática após contágio por COVID- 19

Fernanda Cruz Gonçalves GOMES ${ }^{1}$ (), Christian NAURATH ${ }^{2}$ (ㅇ, Luciane Hiramatsu AZEVEDO $^{3}$ (1), Denise Maria ZEZELL ${ }^{4}$ (1)

1 - São Leopoldo Mandic, Departamento de Odontopediatria, Campinas, SP, Brazil

2 - Instituto Nacional do Câncer, Rio de Janeiro, RJ, Brazil

3 - Laboratório Especial de Laser em Odontologia, Faculdade de Odontologia, Universidade de São Paulo, SP, Brazil

4 - Instituto de Pesquisas Energéticas e Nucleares, Centro de Lasers e Aplicações, São Paulo, SP, Brazil.

\begin{abstract}
Objective: The purpose of this short communication is to show that although photobiomodulation in the treatment of neurophathic oral pain after COVID-19 contagion could be an option, photobiomodulation is not a new technique. PBMT was used with different protocols and pain was assessed using VAS (visual analogue scale - 0 until 10) before and after the consultation. Results: Evolution of VAS during the sessions showed a decrease in painful symptomatology as treatment was performed. Conclusion: Based on the results obtained in the present case report, we concluded that PBMT with the parameters used in this clinical case was an effective, noninvasive and a new option of treatment for neuralgia resulting from COVID-19.
\end{abstract}

\section{KEYWORDS}

Laser; Photobiomodulation therapy; COVID-19; Oral neuralgia.

\section{RESUMO}

Objetivo: O objetivo deste short communication é mostrar que, embora a fotobiomodulação no tratamento de dor oral neuropática após contágio por COVID-19 possa ser uma opção, a fotobiomodulação não é uma técnica recente. TFBM foi utilizado com diferentes protocolos e a dor foi avaliada por EVA (escala visual analógica 0 a 10) antes e após a consulta. Resultados: A evolução da EAV durante as sessões mostrou uma diminuição da sintomatologia dolorosa à medida que o tratamento era realizado. Conclusão: Com base nos resultados obtidos no presente relato de caso, concluímos que a TFBM com os parâmetros utilizados neste caso clínico foi eficaz, não invasivo e uma nova opção de tratamento para a neuralgia decorrente do COVID-19.

\section{PALAVRAS-CHAVE}

Laser; Terapia de fotobiomodulação; COVID-19; Neuralgia oral. 


\section{INTRODUCTION}

The highly infectious coronavirus disease 2019 (COVID-19), caused by coronavirus 2 (SARS-CoV-2), results in severe acute respiratory complications. First reported in Wuhan, Hubei Province, China, Covid-19 has rapidly led to a worldwide pandemic far beyond the boundaries of China [1].

Viral infections are capable of compromising neurological function and could lead to severe nerve damage. In the present coronavirus (CoV) pandemic, numerous patients have suffered severe respiratory failures attributed to SARS-CoV-2, which has been shown to have neurotrophic properties that were possibly able cause neurological diseases. There have been reports of $\mathrm{CoV}$ being found in the brain or cerebrospinal fluid. As the pathobiology of the above-mentioned neuroinvasive viruses has not yet been completely elucidated, it is necessary to investigate the potential effects of $\mathrm{CoV}$ infections on the nervous system [2].

In a systematic review of the literature on the neurologic disorders arising from $\mathrm{CoV}$ infection, 79 studies were selected for qualitative synthesis and 63 , for meta-analysis. The data obtained revealed percentages ranging from over $36 \%$ to $1.5 \%$ of a wide variety of over 15 extremely disturbing manifestations. Among those mentioned were serious conditions such as cerebral vascular disease, encephalitis intracerebral hemorrhage, through to milder conditions such as taste disorders, headaches and dizziness [3].

Photobiomodulation therapy (PBMT), for therapeutic management of neuropathic orofacial pain, was discussed in a systematic review in which this treatment modality was presented as an effective option for different neuropathic orofacial pain entities such as trigeminal neuralgia, occipital neuralgia, and burning mouth syndrome as a single treatment or combined with another treatment [4].

The use of PBMT promotes a favorable prognosis in the regeneration of peripheral nerves in both neurosensory and neuromotor deficits. Irradiating body parts with a laser produces both local and systemic effects that can enhance the nerve regeneration process [5]. Furthermore, appropriate conditions of laser use (wavelength, energy, power, spot and exposure time) are capable of helping to heal peripheral nerve injuries and diminish the trend toward worsening the degeneration of neurons in the spinal cord segments affected by trauma [6].

This case report evaluated the effect of PBMT at the affected site in a patient who developed neuralgia after contagion by COVID-19.

\section{CASE PRESENTATION}

The patient, a 41-year-old man, had a medical history of controlled hypertension, including changes in cholesterol and triglyceride indices. Medications used were $50 \mathrm{mg}$ losartan per day and omega 3. Patient arrived at dental office with a complaint of neuropathic pain in the mandible and was more intense in the anterior region of the maxilla, which started after he was infected by the SARS-COV-2 virus, 60 days previously.

The symptoms presented during the COVID-19 were fever, nasal congestion, myalgia and anosmia, which were initially diagnosed as sinusitis and treated with azithromycin $500 \mathrm{mg}$, fexofenadine hydrochloride $120 \mathrm{mg}$ and Prednisone $20 \mathrm{mg}$ for 5 days. After 7 days without remission of symptoms and the appearance of neuropathy in the jaws, the COVID test was performed by nasopharyngeal swab PCR, which was positive. After this, the patient was medicated with Clavulin BD Amoxicillin/ clavulanic acid $875 \mathrm{mg}$ one tablet per day for 7 days and Pregabalin $50 \mathrm{mg}$ twice a day. The patient reported waking up with mild pain, which was exacerbated throughout the day, in moments of greater anxiety.

The magnetic resonance imaging of the skull and clinical exams, panoramic and periapical radiography of the maxillary and mandibular incisors, showed no alterations.

The PBMT was performed using a low-power laser diode (Laser duo, MMO Equipamentos, São Carlos, Brazil) starting with $4 \mathrm{~J}$ energy at the infrared $(808 \mathrm{~nm})$ intraorally on 69 points (Figure 1): 2 points in the pterygomaxillary region and 2 points on the mental nerve, right and left ( 8 points); 2 points in the right and left retromolar region (4 points), 1 point on the incisive papilla on the palate side and 2 points in the vestibular region (alveolar ridge) per tooth (28 teeth - 56 points). (Table 1 - Phase 1 ). The photobiomodulation protocols were based on a 


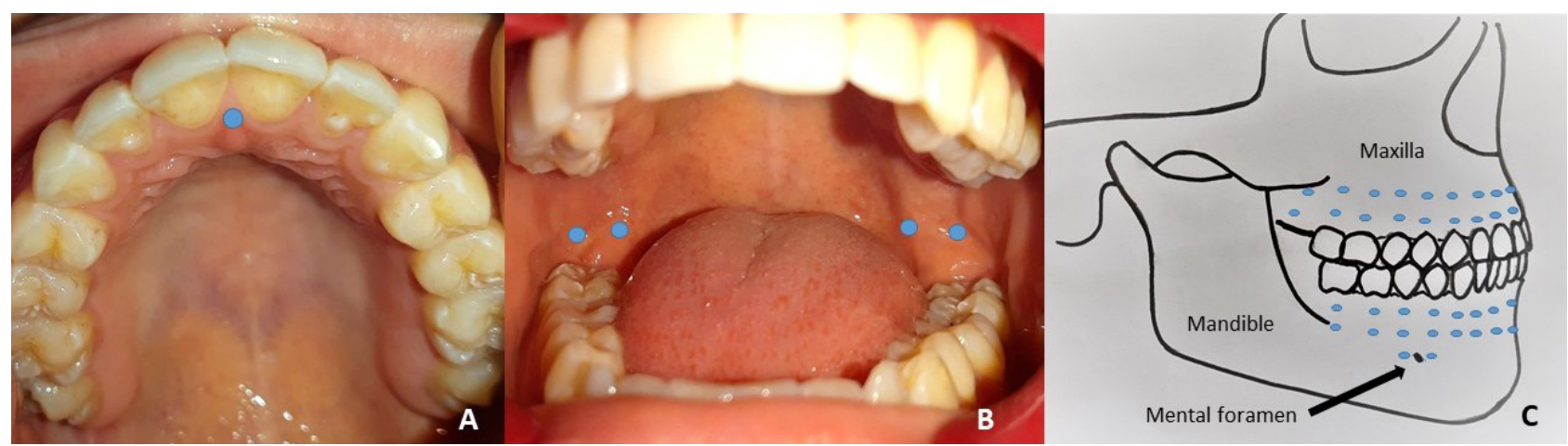

Figure 1 - A-C. Points of laser application used in the treatment. A - One point on the incisive papilla on the palate side. B - Two points in the right and left retromolar region (four points). C - Two points in the pterygomaxillary region, two points on the mental nerve, right and left (eight points) and two points in the vestibular region (alveolar ridge) per tooth (twenty-eight teeth - fifty-six points)

Table I - Laser Parameters Used for the Treatment of Neuralgia

\begin{tabular}{|c|c|c|c|c|c|c|c|c|}
\hline Phases & $\begin{array}{c}\text { Wavelength } \\
(\mathrm{nm})\end{array}$ & $\begin{array}{l}\text { Power } \\
\text { (W) }\end{array}$ & $\begin{array}{c}\text { Energy per } \\
\text { point (J) }\end{array}$ & $\begin{array}{l}\text { Time } \\
\text { (sec) }\end{array}$ & $\begin{array}{l}\text { Energy den- } \\
\text { sity }\left(\mathrm{J} / \mathrm{cm}^{2}\right)\end{array}$ & $\begin{array}{l}\text { Power density } \\
\qquad\left(\mathrm{W} / \mathrm{cm}^{2}\right)\end{array}$ & $\begin{array}{l}\text { No. of } \\
\text { points }\end{array}$ & $\begin{array}{c}\text { Spot size } \\
\left(\mathrm{cm}^{2}\right)\end{array}$ \\
\hline 1 & 808 & 0.1 & 4 & 40 & 133.33 & 3.33 & 69 & 0.03 \\
\hline 2 & 808 & 0.1 & 5 & 50 & 166.66 & 3.33 & 69 & 0.03 \\
\hline 3 & $660-808$ & 0.2 & $2-2$ & 20 & 40.65 & 2.03 & 60 & 0.0984 \\
\hline
\end{tabular}

published study (nerve injuries) [7]. Before and after treatment sessions, VAS (visual analogue scale - 0 until 10) was used to assess pain.

In the first session, initial pain was 2 and at the end of irradiation it remained at level 2 . In the second session, the initial pain was 2 and the final, 1. Pregabalin dose was reduced to $50 \mathrm{mg}$ overnight between second and third consultations. At the beginning of third session, the pain reported was 3 and at the end, 1 . The time interval between the first, second, third and fourth sessions was three days between each of the mentioned sessions. After the fourth session, time interval between consultations was 7 days, and the patient had pain level 2 at the beginning of photobiomodulation and 1 , at the end.

Between the fifth and sixth sessions of laser irradiations, an attempt was made to completely discontinue Pregabalin, which led to exacerbation of painful symptoms to level 6 . At this time, a new protocol was adopted with a higher energy, $5 \mathrm{~J}$ infrared (Table I - Phase 2). The patient felt uncomfortable in this new protocol. During the consultation, patient reported stitches between teeth 12 and 13 and grade 2 pain at the end of the consultation. In the sixth session the protocol was changed again, in an endeavor to improve the treatment with the use of another protocol. At this time, the protocol was the same as that used in the study of Bernal Rodrigues et al
Table II - Evolution of VAS during the sessions with lasers

\begin{tabular}{|ccc|}
\hline Session & VAS before & VAS after \\
\hline First & 2 & 2 \\
\hline Second & 2 & 1 \\
\hline Third & 3 & 1 \\
\hline Fourth & 2 & 1 \\
\hline Fifth & 6 & 2 \\
\hline Sixth & 2 & 1 \\
\hline Seventh & 2 & 1 \\
\hline Eighth & 2 & 1 \\
\hline Ninth & 1 & 0 \\
\hline
\end{tabular}

(facial paralysis) [8]. A diode laser (Therapy EC DMC, São Carlos, Brazil) was used, consisting of $2 \mathrm{~J}$ red $(660 \mathrm{~nm})$ and $2 \mathrm{~J}$ infrared $(808 \mathrm{~nm})$ simultaneously (Table I - Phase 3 ). In this session, the pain grade was 2 at the beginning and grade 1 at the end. Between the seventh and the eighth session the medication was withdrawn; the patient had constant grade 2 and at the end, it was grade 1 . In the ninth session the pain started at grade 1 and at the end, the grade was 0 . It was maintained 69 points of irradiation.

The patient has been followed-up for 8 months and has not used Pregabalin again. His pain level has remained at grade 0 .

The development of the VAS pain grade may be visualized in Table II. 
A written term of informed consent was obtained from the patient to dislose this clinical case.

\section{DISCUSSION}

Infections resulting from $\mathrm{CoV}$ have been found to affect the nervous system and it is now believed that $\mathrm{CoV}$ acting in conjunction with mechanisms of the host immune system could transform these conditions into persistent neurological disorders. Therefore, patients with $\mathrm{CoV}$ infections must be submitted to examinations at an early stage if they have suspected neurological symptoms, including headache, consciousness disorder, paresthesia, neuralgias and any other pathological signs and symptoms. The cerebrospinal fluid of patients in critical condition must be examined without delay, and health care professionals must be made aware of the possible neurological complications that may arise from CoV infection, and their management, in order to ensure the best possible prognosis [1].

A review of literature and a recent systematic review have considered the possibility of using PBMT in the treatment of trigeminal neuralgia, since laser is known to relieve pain without producing side effects. This could be of particular help to patients with intolerance to drugs, who suffer from neuralgia $[9,10]$.

In this case report, the patient had been using Pregabalin $50 \mathrm{mg} 2$ times a day and was in constant pain. When undergoing laser treatment, there was a reduction in pain at the end of the majority of sessions. However, when Pregabalin was withdrawn, an increase in pain was observed in the fifth session (VAS - 6). The protocol used in the Phase 2 caused discomfort to the patient, due to the switches and the time of treatment (50 s per point) that was longer than it had been in Phase 1. At that point in time, a change was made in the laser parameters, and the protocol used in the study by Bernal Rodrigues et al (facial paralysis) was used [8]. The patient showed improvement in the condition and has remained pain free and without the use of Pregabalin up to the present time (8 months).

When considering the number of patients who develop neurological complications, they are few in comparison with those in whom the respiratory tract is compromised. Nevertheless, in the ongoing pandemic an estimated $50-80 \%$ of the world's population are expected to be infected before they develop herd immunity. This may mean that an extremely high number of patients could become susceptible to neurological disorders [11].

A case report draws attention to postherpetic neuralgia in a COVID-19 patient in the right 10 to 12 lumbar dermatomes. She experienced constant burning pain and she was taking medicine (pregabalin). After 4 months of the onset of a rash, the patient reported that she still had intermittent pain [12]. However, in another case report, the facial pain was resolved with the improvement of COVID-19 [13] . Special attention is needed, as the new coronavirus SARS- CoV- 2 is a possible etiology of secondary neuralgia.

It is important that the treatment with laser begins as soon as possible, as occurred in this case report, due to possibly there will be a faster recovery and pain relief from neuralgia, as has been reported in other studies of other causes of neuralgias $[9,10,14]$.

\section{CONCLUSION}

Based on the results obtained in the present case report, we concluded that PBMT with the parameters used in this clinical case was an effective, noninvasive and a treatment new option for neuralgia resulting from COVID-19.

\section{Declaration of Patient Consent}

The authors hereby declare that they have gathered all necessary consent forms from the patient showing his full authorization to use his clinical information in the journal. The patient acknowledges that his name and initials will not be published publicly, and extra efforts will be made to keep identities unknown. Nevertheless, it is not possible to ensure this anonymity fully and absolutely.

\section{Conflict of interest}

No conflicts of interest declared concerning the publication of this article.

\section{Funding}

This research did not receive any specific grant from funding agencies in the public, commercial, or not-for-profit sectors. 


\section{Regulatory Statement}

The authors hereby declare that they have gathered all necessary consent forms from the patient showing her full authorization to use his images and further clinical information in the journal. The patient acknowledges that his name and initials will not be published publicly and extra efforts will be made to keep identities unknown.

Nevertheless, this anonymity cannot be, by any chance, ensured.

\section{REFERENCES}

1. Zhu N, Zhang D, Wang W, Li X, Yang B, Song J, et al. A novel coronavirus from patients with pneumonia in China, 2019. N Engl J Med. 2020;382(8):727-33. http://dx.doi.org/10.1056/ NEJMoa2001017. PMid:31978945.

2. Wu Y, Xu X, Chen Z, Duan J, Hashimoto K, Yang L, et al. Nervous system involvement after infection with COVID-19 and other coronaviruses. Brain Behav Immun. 2020;87:18-22. http://dx.doi. org/10.1016/j.bbi.2020.03.031. PMid:32240762.

3. Tsai ST, Lu MK, San S, Tsai CH. The neurologic manifestations of coronavirus disease 2019 pandemic: a systemic review. Front Neurol. 2020;11:498. http://dx.doi.org/10.3389/ fneur.2020.00498. PMid:32574246.

4. de Pedro M, López-Pintor RM, de la Hoz-Aizpurua JL, Casañas E, Hernández G. Efficacy of low-level laser therapy for the therapeutic management of neuropathic orofacial pain: a systematic review. J Oral Facial Pain Headache. 2020;34(1):1330. http://dx.doi.org/10.11607/ofph.2310. PMid:31339967.

5. Câmara CN, Brito MV, Silveira EL, Silva DS, Simões VR, Pontes RW. Histological analysis of low-intensity laser therapy effects in peripheral nerve regeneration in Wistar rats. Acta Cir Bras. 2011;26(1):12-8. http://dx.doi.org/10.1590/S010286502011000100004. PMid:21271198.
6. Barbosa RI, Marcolino AM, Guirro RRJ, Mazzer N, Barbieri CH, Fonseca MCR. Comparative effects of wavelengths of lowpower laser in regeneration of sciatic nerve in rats following crushing lesion. Lasers Med Sci. 2010;25(3):423-30. http:// dx.doi.org/10.1007/s10103-009-0750-8. PMid:20135336.

7. de Oliveira RF, da Silva AC, Simões A, Youssef MN, de Freitas PM. Laser therapy in the treatment of paresthesia: a retrospective study of 125 clinical cases. Photomed Laser Surg. 2015;33(8):41523. http://dx.doi.org/10.1089/pho.2015.3888. PMid:26226172.

8. Rodriguez CGB, Polho IB, Azevedo LH, Eduardo CP Photobiomodulation therapy to treat facial paralysis of 8 years: case report. Photobiomodul. Photomed Laser Surg. 2020;38(8):477-80. http://dx.doi.org/10.1089/ photob.2019.4763. PMid:32716761

9. Falaki F, Nejat AH, Dalirsani Z. The effect of low-level laser therapy on trigeminal neuralgia: a review of literature. J Dent Res Dent Clin Dent Prospects. 2014;8(1):1-5. http://dx.doi. org/10.5681/joddd.2014.001. PMid:25024832.

10. Ibarra AMC, Biasotto-Gonzalez DA, Kohatsu EYI, de Oliveira SSI, Bussadori SK, Tanganeli JPC. Photobiomodulation on trigeminal neuralgia: systematic review. Lasers Med Sci. 2021;36(4):715-22. http://dx.doi.org/10.1007/s10103-02003198-6. PMid:33219445.

11. Ellul MA, Benjamin L, Singh B, Lant S, Michael BD, Easton $A$, et al. Neurological associations of COVID-19. Lancet Neurol. 2020;19(9):767-83. http://dx.doi.org/10.1016/S14744422(20)30221-0. PMid:32622375.

12. Cao X, Zhang X, Meng W, Zheng H. Herpes zoster and postherpetic neuralgia in an elderly patient with critical COVID19: a case report. J Pain Res. 2020;13:2361-5. http://dx.doi. org/10.2147/JPR.S274199. PMid:33061551.

13. Molina-Gil J, González-Fernández L, García-Cabo C. Trigeminal neuralgia as the sole neurological manifestation of COVID19: a case report. Headache. 2021;61(3):560-2. http://dx.doi. org/10.1111/head.14075. PMid:33749854.

14. Ebrahimi H, Najafi S, Khayamzadeh M, Zahedi A, Mahdavi A Therapeutic and analgesic efficacy of laser in conjunction with pharmaceutical therapy for trigeminal neuralgia. J Lasers Med Sci. 2018;9(1):63-8. http://dx.doi.org/10.15171/jlms.2018.13. PMid:29399314.

\section{Luciane Hiramatsu Azevedo}

(Corresponding address)

Laboratório Especial de Laser em Odontologia, Faculdade de Odontologia,

Universidade de São Paulo, SP, Brazil.

Email: luazevedo@usp.br

Date submitted: 2021 Apr 19 Accept submission: 2021 June 14 